Iranian Quarterly Journal of Breast Disease. 2019; 12(1):58-66.

\section{Original Article \\ The Relationship Between Social Support and Depression in Patients with Breast Cancer}

\author{
Montazer $M^{1}$, Katani M-R ${ }^{2}$, Sefidmooy Azar $A^{3}$, Mobaraki-Asl $N^{4}$, Dorosti \\ $\mathbf{A}^{5 *}$ \\ ${ }^{1}$ Thorax Group, Tuberculosis and Lung Disease Research Center, Tabriz University of \\ Medical Sciences, Tabriz, Iran \\ ${ }^{2}$ Sina Hospital, Tabriz University of Medical Sciences, Tabriz, Iran \\ 3 Anesthesiology Student, Faculty of Paramedicine, Tabriz University of Medical \\ Sciences, Tabriz, Iran \\ ${ }^{4}$ Gynecology Oncology, Ardabid University of Medical Sciences, Ardabil, Iran \\ ${ }^{5}$ Anesthesia Group, Tabriz University of Medical Sciences, Tabriz, Iran
}

Receive: 2019/1/31 Accepted: $2019 / 3 / 8$

*Corresponding Author: Abbasali Dorosti, Dorostia44@yahoo.com

Ethics Approval: IR.TBZMED.REC.1397. 598

\section{Abstract}

Introduction: The relationship between social support and depression can have implications for the outcome of breast cancer treatment. Therefore, the aim of this study was to examine social support and its relation to depression in women with breast cancer.

Methods: In this descriptive-correlational study performed in Tabriz in 2018. A total of 240 patients with breast cancer who met the inclusion and exclusion criteria were included in the study. The Multidimensional Scale of Perceived Social Support (MSPSS) and Beck Depression Inventory were used for research purposes. The Spearman correlation test was used to determine the relationship between the two variables. A $\mathrm{P}$ value of $<0.05$ was considered significant.

Results: $63 \%$ of women had moderate to severe depression, and mean \pm SD of total social support score was $40.29 \pm 11.99$. Spearman's correlation results indicated a negative relationship between depression and social support $(\mathrm{r}=-512, \mathrm{P}<0.001)$.

Conclusion: The prevalence of moderate to severe depression in the current study sample was high $(63 \%)$, which is consistent with similar studies. On the other hand, women with below average depression had higher perceived social support score, and the correlation between these variables was statistically significant.

Keywords: Depression, Social Support, Breast Cancer 


\section{بررسى ارتباط حمايت اجتماعى و افسردكى در بيماران مبتلا به سرطان يستان: يك مطالعه همبستىى لونى}

مجيد منتظر '، محمدرضا كتانى '، عطا سفيدموى آذر "، نوشين مباركى اصل"، عباسعلى درستى ه"

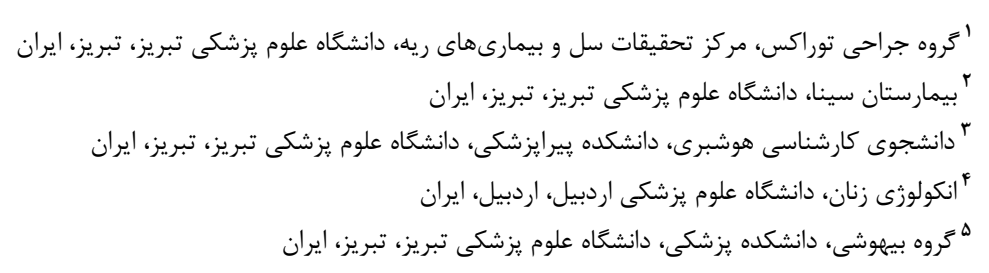

فصلنامه بيمارى هاى بـتان إيران

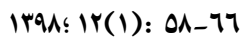

تاريخ ارسال:

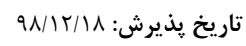

نشانى نويسنده مسئول: عباسعلى درستى نون Dorostia44@yahoo.com

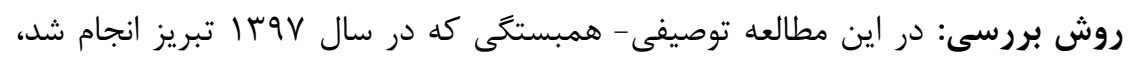

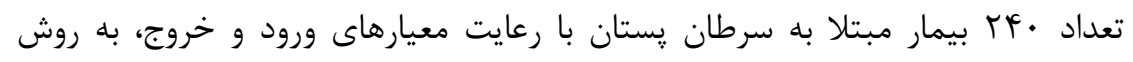

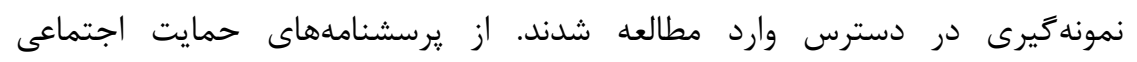

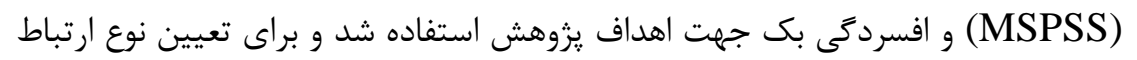

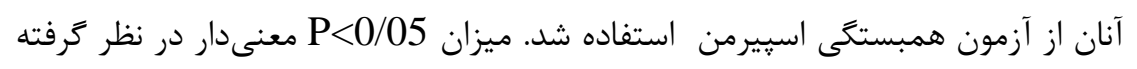

يافتهها: بَو٪ زنان داراى افسردگى متوسط به بالا بودند و ميانگين \pm انحراف معيار نمره

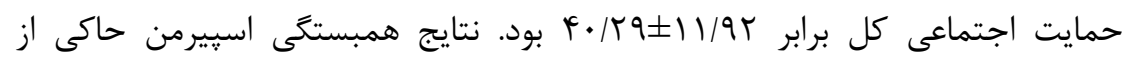

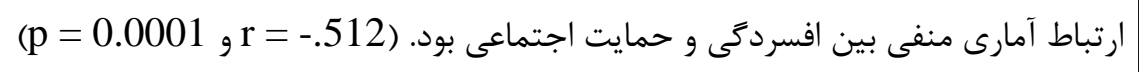

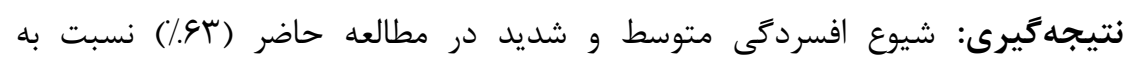

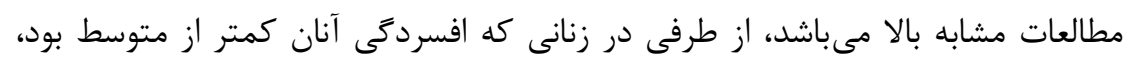

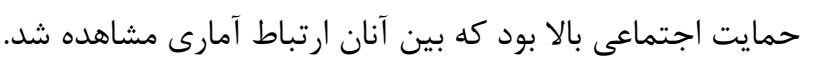
|وازههاى كليدى: افسردگى، حمايت اجتماعى، سرطان : يستان 
همدلى از طرف همسر با علايم افسردكى كمتر در

بازماندًان سرطان يستان سالمند ارتباط دارد (T) (T).

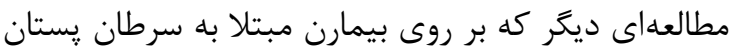
جوان تمركز كرده است به اهميت حمايت خانوادگى بعد از بردي

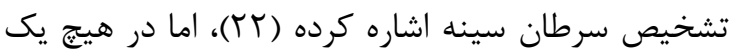
از مطالعات ذكر شده، ميزان تاثيركذارى حمايت اجتماعى لإنى

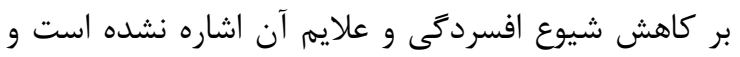
مطالعات مشابه با هدف مقاله حاضر معدود هستند.

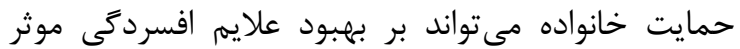

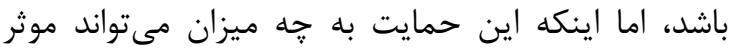

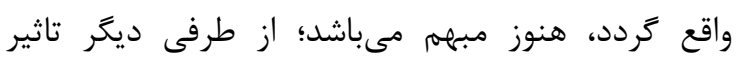

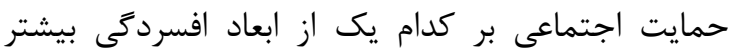

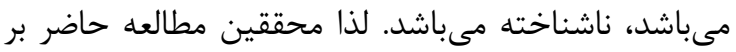

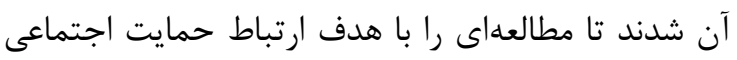

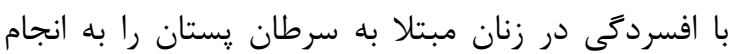
برساند.

\section{مواد و روشها}

مطالعه حاضر از نوع توصيفى -همبستكى است كه در طى

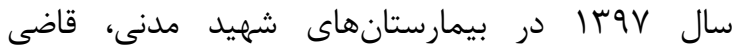

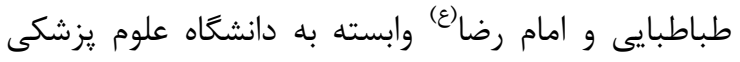
تبريز انجام شد. حجم نمونه بر اساس فرمول كوكران تعيين شد؛ به نحوى كه با در نظر كرفتن حجم جامعه نماند

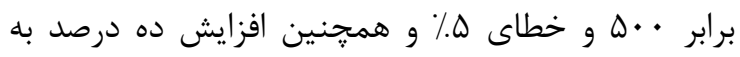

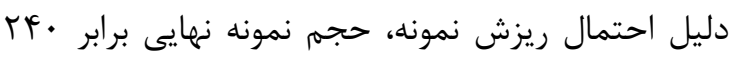

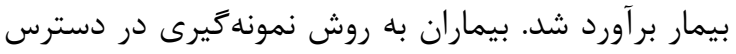
و با رعايت معيارهاى ورود و خروج وارد مطالعه شدند.

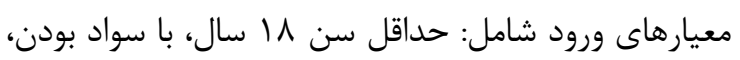
ابتلا به سرطان يستان بودند و معيارهاى خروج شامل: سابقه بيمارى روانى (همجِون اسكيزوفرنى، اختلال شخصيت دو قطبى و ساير اختلالاتى كه بر صحت نتئن موثر هستند) و عدم رضايت به شركت در مطالعه بودند. در اين مطالعه از سه ابزار سنجش شامل קك لئ ليست

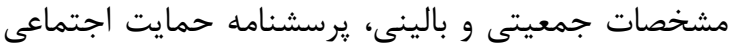
و يرسشنامه بك استفاده شده است. جى ليست مشخصات جمعيتى و بالينى شامل سوالاتى

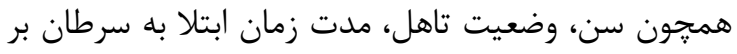

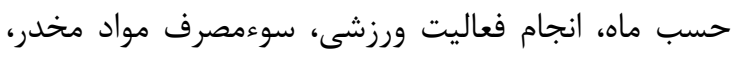
سوءمصرف الكل، عمل جراحى سينه، شيمىدرمانى و
سرطان يستان شايعترين سرطان ميان زنان است (1, $) ،$

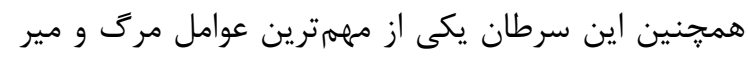

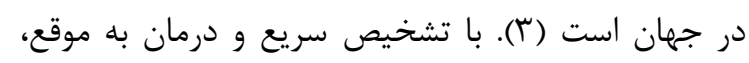

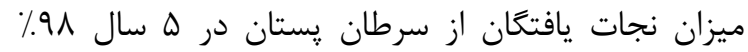

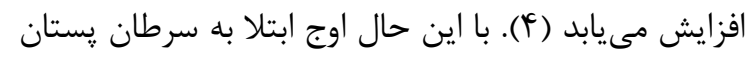

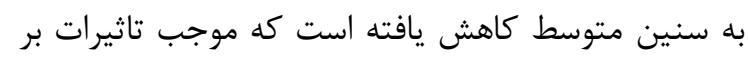
نقشهاى فردى، خانوادگى و اجتماعى زنان شده است (ه). يس تاثير سرطان يستان از لحاظ جسمى، ذهنى و و

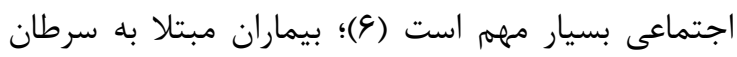

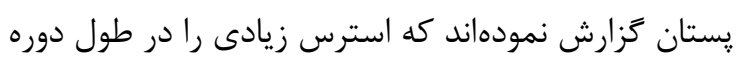

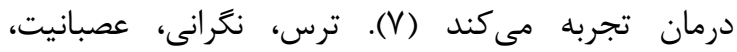
نااميدى نسبت به آينده و شكل بدن، واكنشهاى شائ شايع و

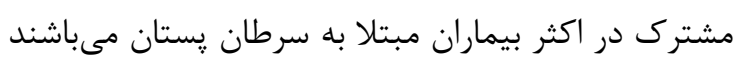

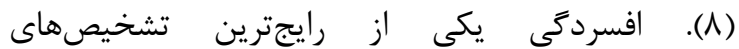
روانشناختى در بين نجات يافتخان سرطان يستان است رات

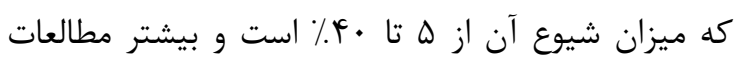

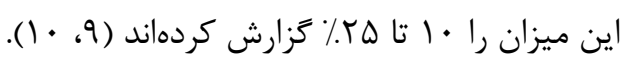

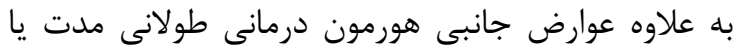

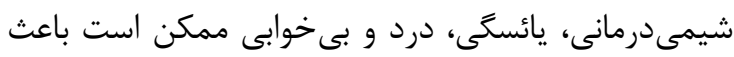

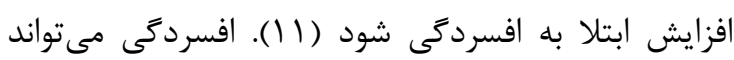
موجب بدتر شدن بيمارى شده و ممكن است باعث إث إثل

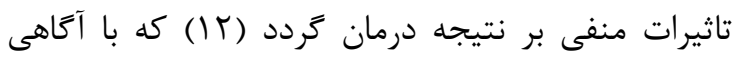

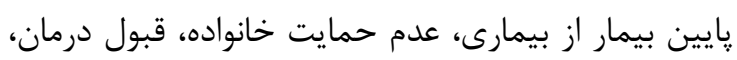
اضطراب، اعتياد به الكل يا تنباكو ارتباط مستقيمى داشته

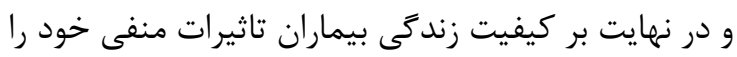

اعمال مى كند (با، عاع (l).

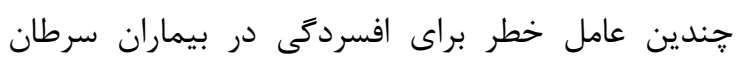

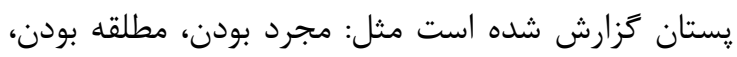

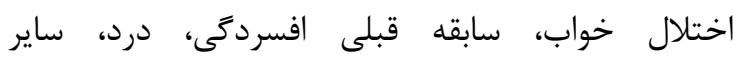

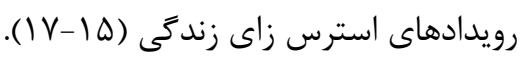

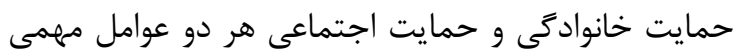
براى بيماران افسرده در جامعه هستند (1) (1). اعضاى خانواده نيز تحت تاثير تغييرات تجربه شده توسط بـان بيمار

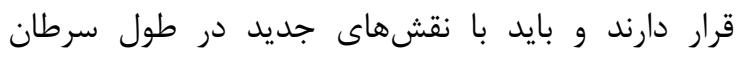

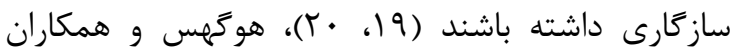

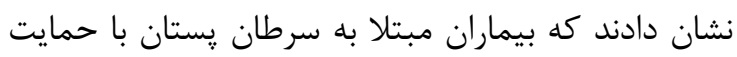

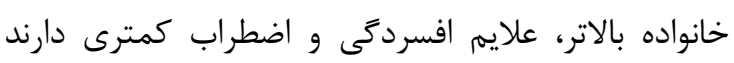

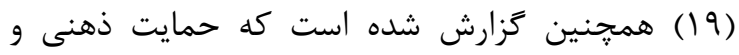


اهداف يزوهشى به بيماران، توضيح محرمانه بودن تمامى المات اطلاعات دريافتى از بيماران، اختيارى بودن تركى مطالعه برانه

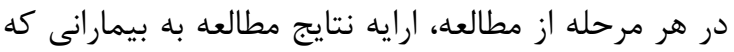

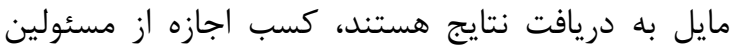

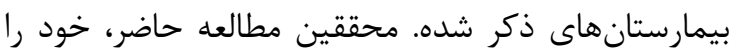
موظف به رعايت تمامى موارد اخلاقى در يزوهش مى دانيد

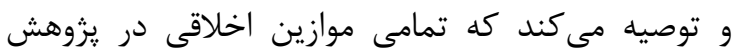
هاى علوم يزشكى توسط محققين رعايت گردد.

SPSS Sادهها پس از جمعآورى وارد نرمافزار آمارى

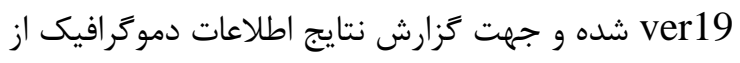

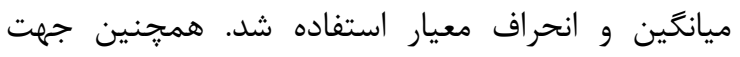

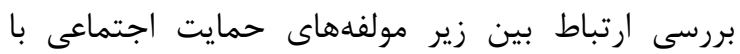

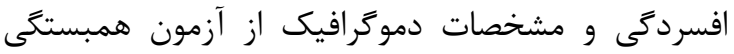

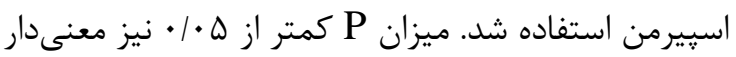

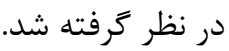

\section{يافتهها}

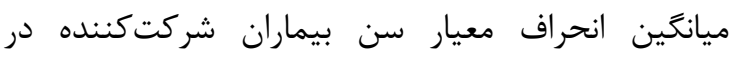

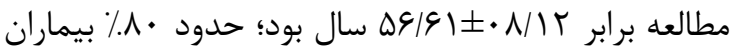

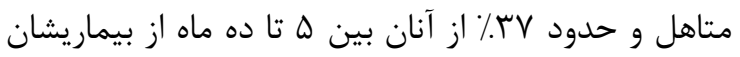

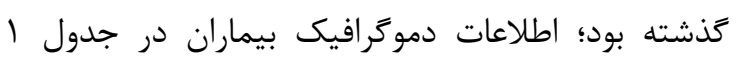

آورده شده است.

جدول ا: مشخصات فردى اجتماعى در بيماران مبتلا به سرطان

\begin{tabular}{|c|c|c|}
\hline \multicolumn{3}{|c|}{ يستان } \\
\hline تعداد (درصد) & & متغير مورد بررسى \\
\hline$\Lambda(T / T r)$ & مجرد & \\
\hline $191(\vee 9 / \Delta \Lambda)$ & متاهل & وضعيت تاهل \\
\hline$f \mid(\mid V / .9)$ & مطلقه & \\
\hline 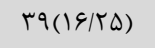 & كمتر از هـ & \\
\hline$\Lambda V(r G / T \Delta)$ & ه ت ا & مدت زمان بيمارى \\
\hline$\varepsilon \Delta(Y V / \cdot \Lambda)$ & . اتا ها. & بر حسب ماه \\
\hline$F q(Y \cdot / F T)$ & Sا & \\
\hline $\operatorname{TrA}(9 \Delta / \cdot \cdot)$ & دارد & \\
\hline $\mid r(\cdot \Delta / \cdot \cdot)$ & 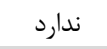 & 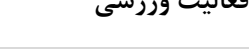 \\
\hline 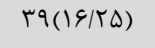 & دارد & \\
\hline$r \cdot l(\Lambda r / V \Delta)$ & 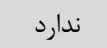 & مصرق مسروبات الحلى \\
\hline$q \cdot(\Gamma \vee / \Delta \cdot)$ & دارد & ساقه ح احج سينه \\
\hline $10 \cdot(\varepsilon / \Delta \cdot)$ & 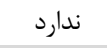 & سابعه بجرامسى سيس \\
\hline $1 \wedge 9(\vee \vee / \Delta \cdot)$ & دارد & \\
\hline$\Delta F(Y Y / \Delta \cdot)$ & 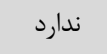 & سابعه سيمى درمانى \\
\hline $\mid \Delta \varphi(\varepsilon \Delta / \cdot \cdot)$ & دارد & 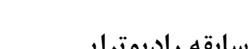 \\
\hline$\Lambda F(r \Delta / \cdot \cdot)$ & 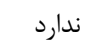 & سابعه راديم \\
\hline
\end{tabular}

راديوترايى بود. قسمت دوم يرسشنامه حمايت اجتماعى

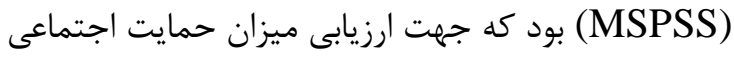
استفاده شد. اين زرسشنامه توسط زيموتن و همكاران در

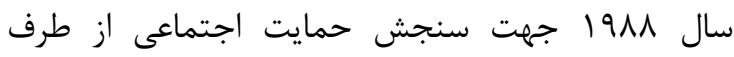
خانواده، دوستان و افراد مهمم زندگى طراحى شده است كه داراى Yl سوال در سه حيطه (حمايت اجتماعى دريافت دان

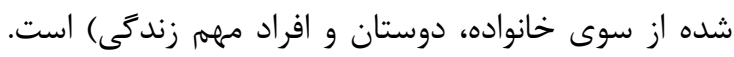

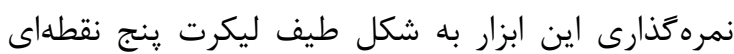
بوده كه كمترين نمره براى جواب كاملا مخالف (نمره () و

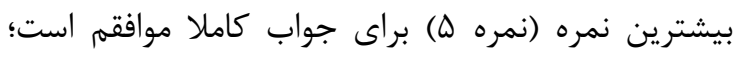

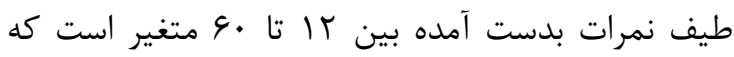

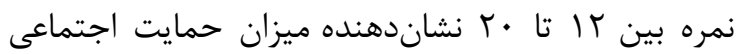

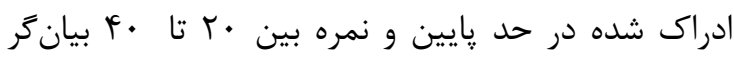

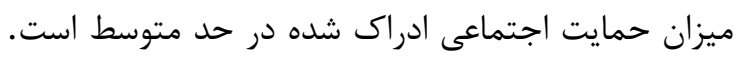

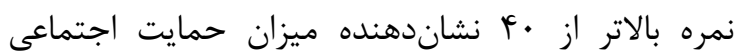
ادراك شده در حد بالا است؛ همجنين طيف نمره هر زير إنان

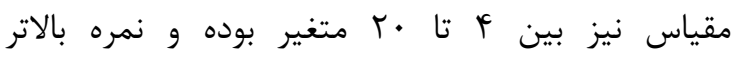

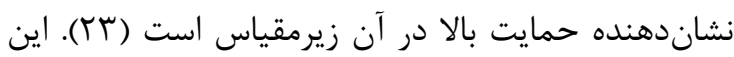
ابزار توسط نظرى و همكاران در ايران مورد استفاده قرار

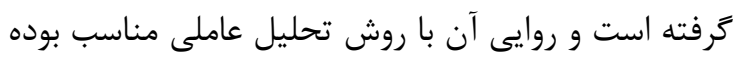

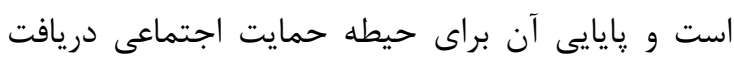

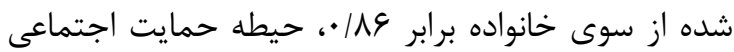

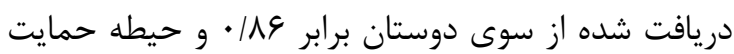

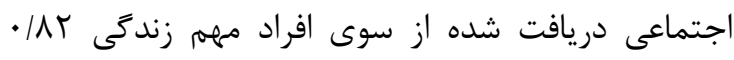

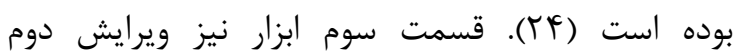

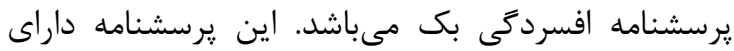

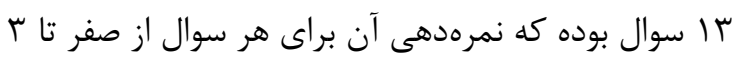

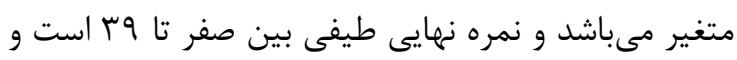

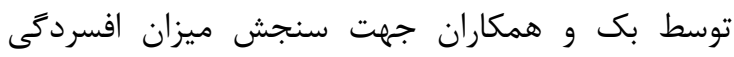

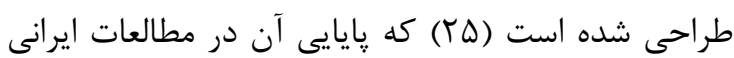

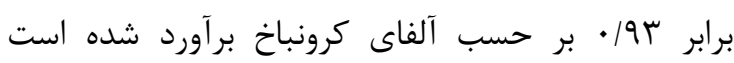

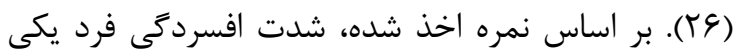

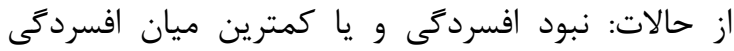

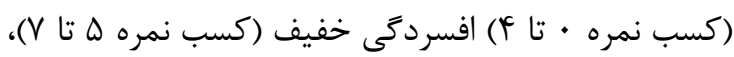

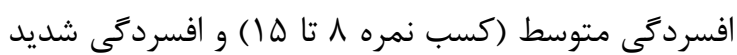

$$
\text { (كسب نمره بيشتر از } 9 \text { (1) خواهد بود نمره }
$$

لازم به ذكر است ملاحظات اخلاقى در مطالعه حاضر

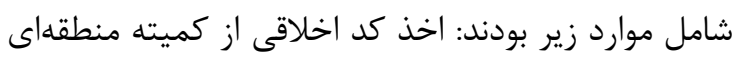
اخلاق، اخذ رضايت آكاهانه از تمامى بيماران، توضيح 
شده در بيماران مبتلا به سرطان يستان در جدول شماره ب آورده شده است.

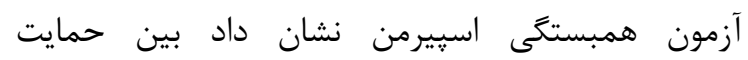

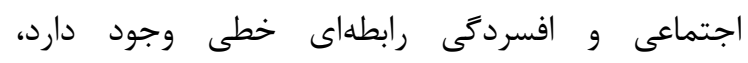
بلهورى كه با افزايش حمايت اجتماعى ميزان افسردىى

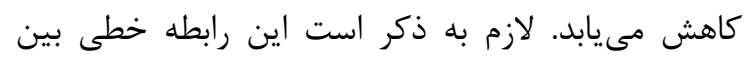

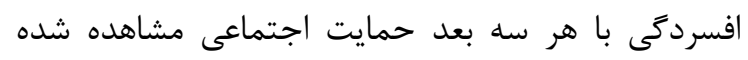

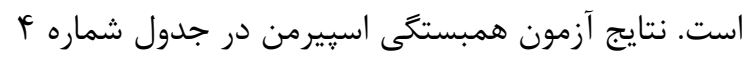
آورده شده است. نتايج آزمون ANOVA بين مشخصات دموكرافيك و و آندات

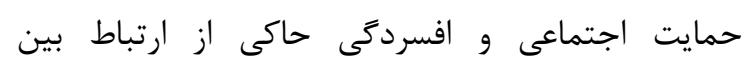

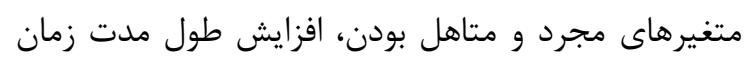

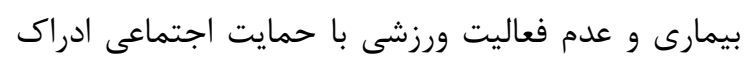

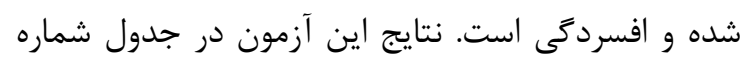
ها ارايه شده است.
نتايج شدت افسركى حاكى از آن بود كه بيشتر از بوء٪

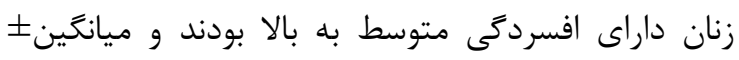

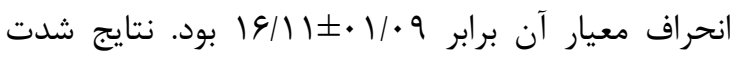

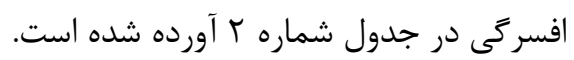

جدول ז: وضعيت افسردمى در بيماران مبتلا به سرطان پِستان

\begin{tabular}{|c|c|}
\hline تعداد (درصد) & وضعيت افسردكى \\
\hline$\mu q(\mid \Delta / \cdot \cdot)$ & هيج يا بسيار كم \\
\hline$\Delta \mid(T \backslash / T \Delta)$ & خفيف \\
\hline$\Lambda 9(\Gamma \mathrm{V} / \cdot \wedge)$ & متوسط \\
\hline $4 \varphi(\Upsilon \varphi \mid 9 V)$ & شديد \\
\hline
\end{tabular}

ميانكين \pm انحراف معيار نمره حمايت اجتماعى كل

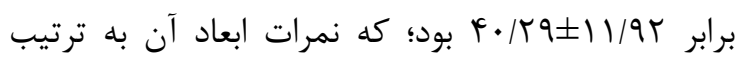

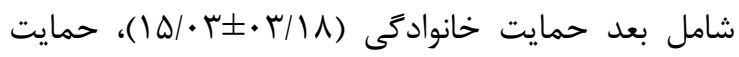

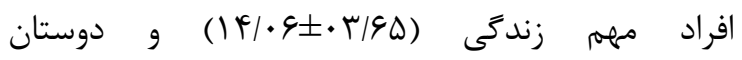

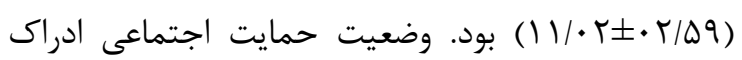

جدول זّ: وضعيت حمايت اجتماعى ادراك شده در بيماران مبتلا به سرطان پِستان

\begin{tabular}{|c|c|c|c|c|}
\hline 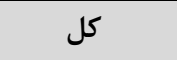 & افراد مهمم زندكى & دوستان & خانواده & حمايت اجتماعى ادراك شده \\
\hline تعداد (درصد) & تعداد (درصد) & تعداد (درصد) & تعداد (درصد) & \\
\hline $9(\cdot r / Y \Delta)$ & $\|(\cdot \Delta / F \mid)$ & $r \cdot(\cdot \Lambda / T r)$ & $\|(\cdot \Delta / f \mid)$ & كاملا مخالفم \\
\hline $1 \Delta(\cdot 9 / K \Delta)$ & $r r(\cdot 9 / 19)$ & $r \Delta(1 \cdot|\psi|)$ & $1 \cdot(\cdot \varphi / 19)$ & مخالفم \\
\hline$r \Delta(\mid \Lambda / V \Delta)$ & $\Delta \cdot(r \cdot / \Lambda r)$ & $r q(19 / \Gamma \Delta)$ & $r(1 Y / 91)$ & 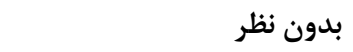 \\
\hline$\Lambda \cdot(\Gamma / T)$ & $99(\Gamma V / \Delta \cdot)$ & $\Lambda 9(\Upsilon V / \cdot \Lambda)$ & $\vee 9(\Gamma 1 / 9 V)$ & 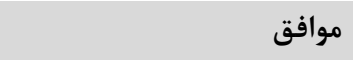 \\
\hline $91(r V / 94)$ & $\wedge ৭(\cdot V / \cdot \wedge)$ & $G V(T V / q T)$ & $11 \cdot\left({ }^{F} \Delta / \Lambda \Gamma\right)$ & خيلى موافق \\
\hline$r F \cdot(1 \cdot)$. & $r F \cdot(1 \cdot)$. & $r F \cdot(1 \cdot \cdot)$ & $r F \cdot(1 \cdots)$ & جمع \\
\hline
\end{tabular}

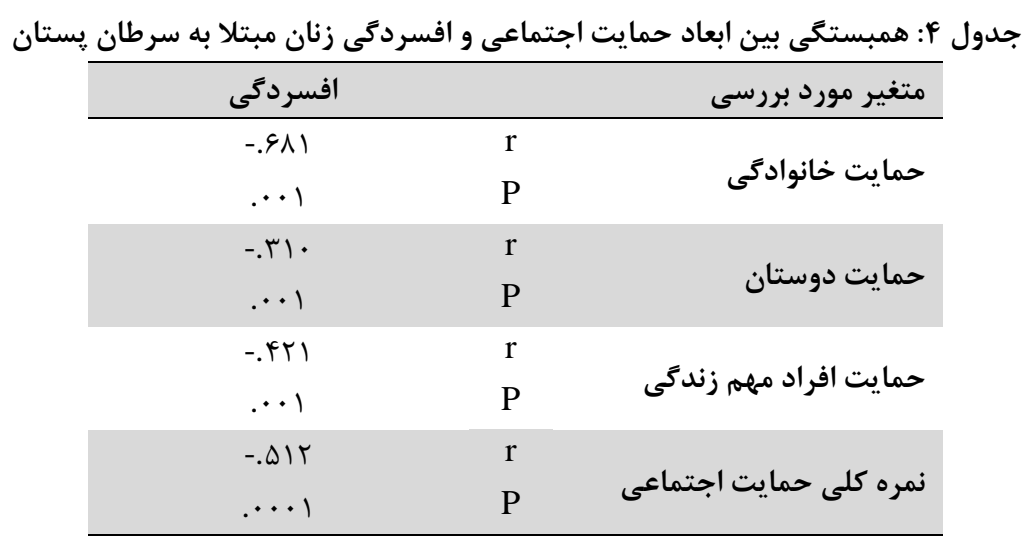




\begin{tabular}{|c|c|c|c|c|c|}
\hline \multicolumn{2}{|r|}{ افسردَى } & \multicolumn{2}{|r|}{ حمايت اجتماعى } & & \multirow[t]{2}{*}{ متغير مورد بررسى } \\
\hline $\mathbf{p}$ & ميانغين(انحراف معيار) & $\mathbf{p}$ & ميانغين(انحراف معيار) & & \\
\hline \multirow{3}{*}{$\cdot 1 \cdot \cdot 1$} & $\mid r / \cdot r \pm \cdot 1 / \cdot 1$ & \multirow{3}{*}{$\cdot / \cdot r$} & $r q / 11 \pm \cdot 9 / r \Delta$ & مجرد & \multirow{3}{*}{ وضعيت تاهل } \\
\hline & $\mid Q / 9 \& \pm \cdot 1 / 1 \wedge$ & & $F r / Q \cdot \pm I Y / \cdot r$ & متاهل & \\
\hline & $r \cdot / 19 \pm \cdot r / r$ & & $\kappa \Delta / 11 \pm 1 r / q$. & مطلقه & \\
\hline \multirow{4}{*}{$\cdot / \cdot \mathrm{l}^{\mathrm{f}}$} & $\cdot 9 / \cdot 9 \pm \cdot \cdot / 19$ & \multirow{4}{*}{$\cdot|\cdot r|$} & $r \cdot / \& q \pm \cdot V / r \Delta$ & كمتر از هـ & \multirow{4}{*}{ مدت زمان بيمارى } \\
\hline & $11 / r q \pm \cdot 1 / \cdot \cdot$ & & $r \varepsilon / r \Delta \pm \cdot q / q)$ & ه تا · & \\
\hline & $\mid V / 09 \pm \cdot 1 / 11$ & & $f \mid / r \Delta \pm 1 \cdot / 11$ & • اتا ها & \\
\hline & $19 / 7 \wedge \pm \cdot 1 / 9$. & & $F \Delta / T E \pm I T / I T$ & $r \cdot r$ Q & \\
\hline \multirow{2}{*}{$\cdot 1 \cdot 1$} & $|r /| r \pm \cdot 1 / \cdot \cdot$ & \multirow{2}{*}{$\cdot 1 \cdot 1$} & TG/TGE. Q/AF & 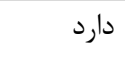 & \multirow{2}{*}{ فعاليت ورزشى } \\
\hline & $r \cdot|r| \pm \cdot 1 / r q$ & & $F F / r \cdot \pm \mid r / \cdot r$ & 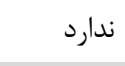 & \\
\hline \multirow{2}{*}{$\cdot / \Lambda \Delta$} & $r r / r q \pm \cdot 1 / q r$ & \multirow{2}{*}{$\cdot / 9$} & $F|/| f \pm \| 1 / \cdot r$ & 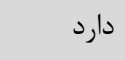 & \multirow{2}{*}{ الكلى مصرف مشروبات } \\
\hline & $1 \cdot 1 \cdot 9 \pm \cdot \cdot / 14$ & & $r q / r \cdot \pm 11 / 19$ & 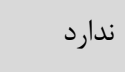 & \\
\hline \multirow{2}{*}{$\cdot 1 \cdot r \Delta$} & & \multirow{2}{*}{$\cdot 1 \cdot \cdot 1$} & & دارد & \multirow{2}{*}{ سابقه جراحى سينه } \\
\hline & $r \cdot / r \Delta \pm \cdot 1 / 9$. & & $F T / / r \pm I Y / I r$ & 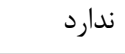 & \\
\hline \multirow{2}{*}{$\cdot 1 \cdot 1$} & $\Gamma 1 / F \Delta \pm \cdot 1 / q$. & \multirow{2}{*}{$\cdot / \cdot r$} & $r F / / r \pm \| r / \mid Q$ & دارد & \multirow{2}{*}{ سابقه شيمىدرمانى } \\
\hline & $\| / 11 \pm \cdot 1 / A r$ & & $\mid r q / \cdot 9 \pm \cdot 1 / 19$ & 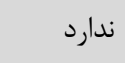 & \\
\hline \multirow{2}{*}{$\cdot / \cdot r \Delta$} & $r \cdot / 9 \wedge \pm \cdot 1 / / Q$ & \multirow{2}{*}{$\cdot / \cdot r$} & $F \Delta /|q \pm| \Delta / r \mid$ & دارد & \multirow{2}{*}{ سابقه راديوترايى } \\
\hline & $|r /| r \pm \cdot I / V T$ & & $r \Delta / \Delta 1 \pm 1 \cdot 1 \cdot 9$ & ن ل & \\
\hline
\end{tabular}

زاينال و همكاران، ميسر نيست و محققين انجام مطالعات

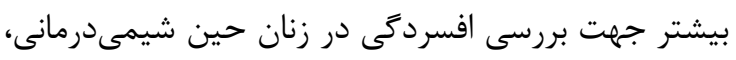

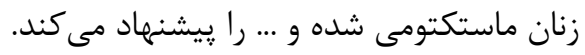

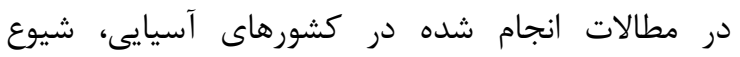

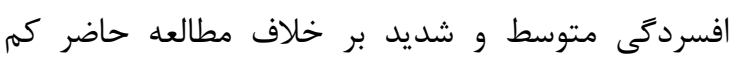
مىباشد و همجنين شيوع شدت افسردىى در كشورهاى

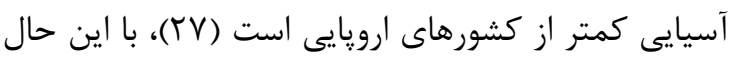

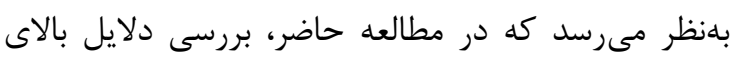

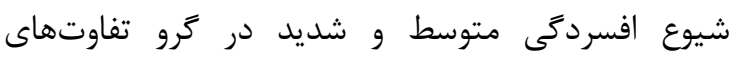
فرهنگى زنان جامعه ما با ساير زنان در كشورهاى ديكر

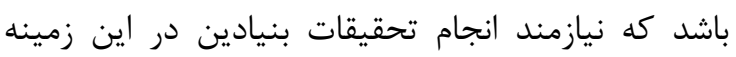

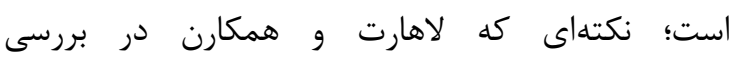
إيدميولوزيكى دلايل افسردىى در زنان مبتلا به سرطان يستان به آن اشاره كرده است (ه) (ه).

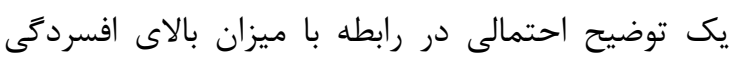

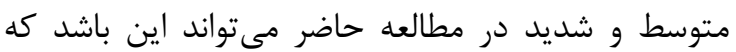
قوميتهاى مختلف نسبت به بيمارى، ياسخهاى متفاوتى

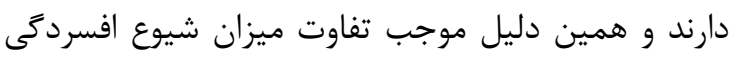

هدف از مطالعه حاضر افسردىى و حمايت خانوادگى در بيماران مبتلا به سرطان سينه است. در مطالعه ما، ميزان شيوع اختلال افسردكى متوسط به بالا در بين بيماران

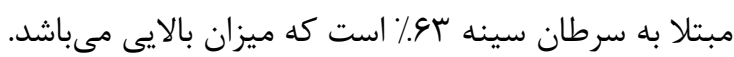

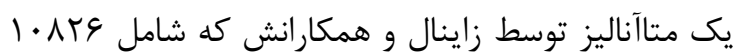
بيمار مبتلا به سرطان سينه از Tr مط مطالعه تحقيقاتى

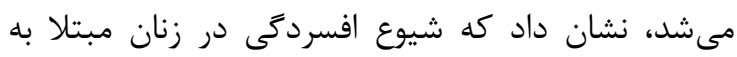

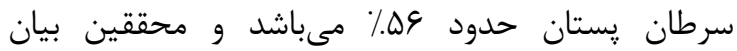
مى كند كه عوامل بسيار زيادى بر شيوع افسردكى در زنان

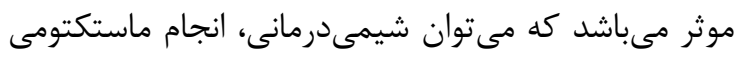

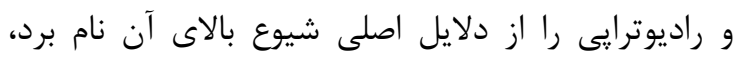

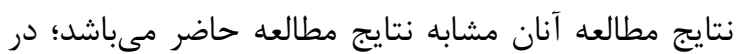

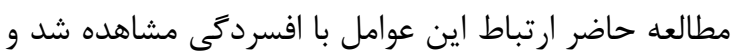

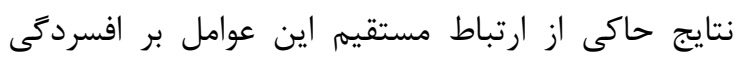

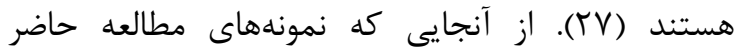

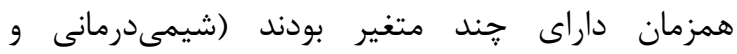

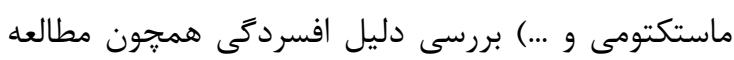


همجنين سالاكارى و همكاران نيز در مطالعه خود بر اثرات

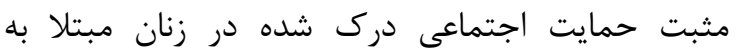
سرطان يستان و ارتباط آن با شيوع افسردكى اشاره

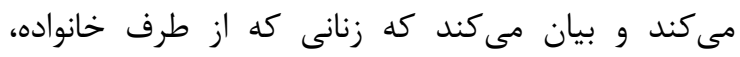

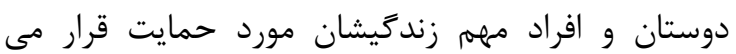
گيرند نسبت به ساير زنان در مقابله با بيماريشان قوىتر

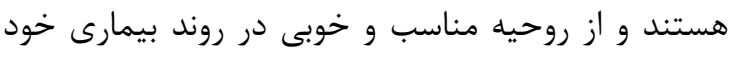
برخوردارند (آ⿱). نتايج مطالعه آنان نيز با مطالعه حاضر به دونه دليل تشويقها و حمايتهاى اطرافيان در ادامه روند درمانى و ارزشمندى بيماران براى افراد مههم زندگى همسو بوده و در يك راستا مىباشند. در مطالعه ما تعدادى از محدوديتها وجود دارد. اول اين

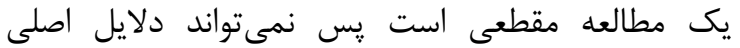
افسردىى را در زنان يافت. دوم؛ عدم توجه به قوميت زنان اندان

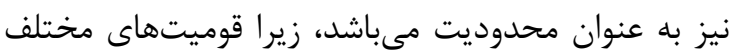
نسبت به مبارزه با بيمارى پاسخهاى متفاوتى را بروز مى دهند

\section{نتيجهگيرى}

شيوع افسردگى متوسط و شديد در مطالعه حاضر بالا

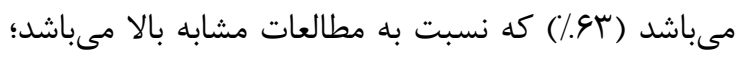

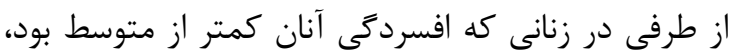

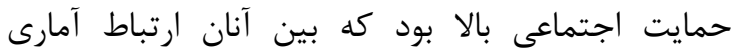

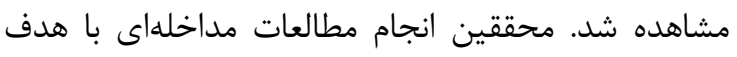

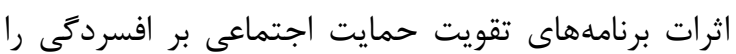
در مطالعات آتى بيشنهاد مى كند.

\section{تشكر و قدردانى}

مقاله حاضر بركرفته از يروهش مصوب در مركز تحقيقـات

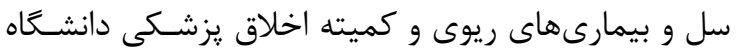

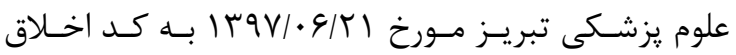
شماره IR.TBZMED.REC.1397. 598 مى باشد.

\section{تعارض منافع}

نويسندكان اعلام مى دارند كه هيج تعارض منافعى در ئزوهش حاضر وجود ندارد.
در كشورهاى مختلف است، البته اين موضوع نيازمند بررسىهاى تحقيقاتى بيشتر است.

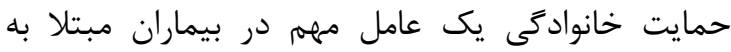

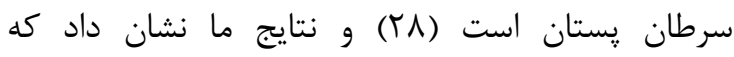
حمايت خانوادگى با افسردگى ارتباط معكوسى دارد بdطورى كه هرجه حمايت (p=0.0001, r= -.512) خانوادگى بيشتر باشد ميزان افسردگى كمتر است. در يكى

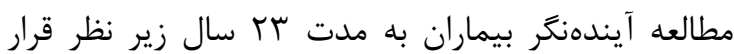
داشتند و نتايج حاكى از آن بود كه زنانى كه از حمايت بالاى خانوادگى برخوردارند نسبت به ساير زنان مبتلا به آنا

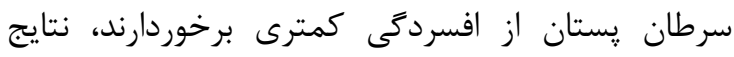
مطالعه آنان با مطالعه حاضر همسو نبوده و در يك راستا نيست، زيرا حمايت اجتماعى مىتواند با اثرات مثبتى كه دهان بر اميد به زندگى و حمايت در ادامه روند درمان داشته

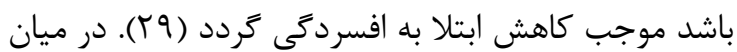

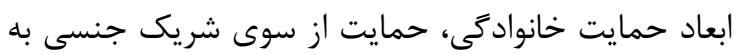

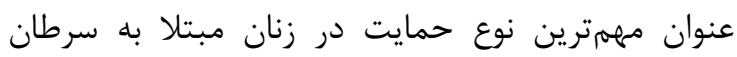

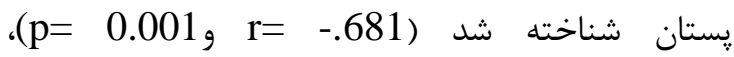
بلاطورى كه زنانى كه از حمايت همسر برخوردار بودند، علايم افسردىى در آنان وجود نداشت (·ـآ). نتايج مطالعه حاضر همجون مطالعات قبلى انجام شده حاكى آنى از اثردات

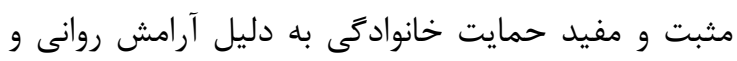
اثرات مثبت افراد خانواده در افزايش روحيه مثبت بيماران

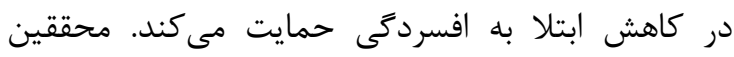
انجام مطالعات با بررسى اثرات افزايش حمايت اجتماعى إنى

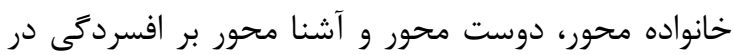
اين بيماران را ي يشننهاد مى كند.

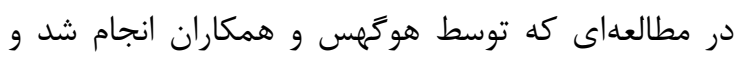

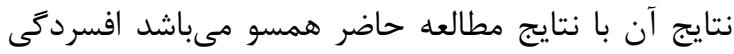
در ميان زنانى كه داراى حمايت اجتماعى درك شده

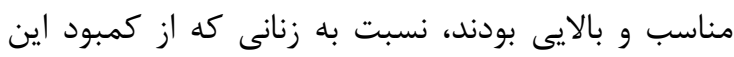

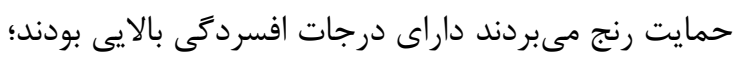
محققين جنين معتقدند كه با افزايش حمايتهاى

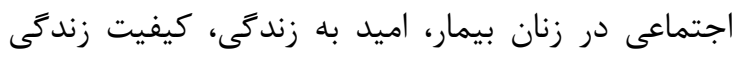

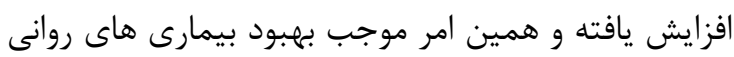
در اين زنان مى كردد (19). 


\section{References}

1. Myers ER, Moorman P, Gierisch JM, Havrilesky LJ, Grimm LJ, Ghate S, et al. Benefits and harms of breast cancer screening: a systematic review. Jama. 2015; 314(15): 1615-34.

2. Khanbabayi Gol M, Arefi N, Jafari M, Farzin H, Aghamohammadi D. Prevalence of PortRelated Infections and Their Predisposing Factors in Women with Breast Cancer under Chemotherapy. Iranian Quarterly Journal of Breast Diseases. 2018;11(2):7-15.

3. Dyrstad SW, Yan Y, Fowler AM, Colditz GA. Breast cancer risk associated with benign breast disease: systematic review and metaanalysis. Breast cancer research and treatment. 2015; 149(3):569-75.

4. DeSantis C, Ma J, Bryan L, Jemal A. Breast cancer statistics, 2013. CA: a cancer journal for clinicians. 2014; 64(1):52-62.

5. Smith SG, Sestak I, Forster A, Partridge A, Side L, Wolf M, et al. Factors affecting uptake and adherence to breast cancer chemoprevention: a systematic review and meta- analysis. Annals of Oncology. 2015; 27(4):575-90.

6. Lahart IM, Metsios GS, Nevill AM, Carmichael AR. Physical activity, risk of death and recurrence in breast cancer survivors: a systematic review and metaanalysis of epidemiological studies. Acta Oncologica. 2015; 54(5):635-54.

7. Hecht F, Pessoa CF, Gentile LB, Rosenthal D, Carvalho DP, Fortunato RS. The role of oxidative stress on breast cancer development and therapy. Tumor biology. 2016; 37(4): 4281-91.

8. Hassan MR, Shah SA, Ghazi HF, Mohd Mujar N, Samsuri MF, Baharom N. Anxiety and depression among breast cancer patients in an urban setting in Malaysia. Asian Pac J Cancer Prev. 2015; 16(9):4031-5.

9. Cvetković J, Nenadović M. Depression in breast cancer patients. Psychiatry research. 2016; 240(3):343-7.

10. Sun H-L, Dong X-X, Cong Y-J, Gan Y, Deng $\mathrm{J}$, Cao S-Y, et al. Depression and the risk of breast cancer: a meta-analysis of cohort studies. 2015.

11. Dodd MJ, Cho MH, Cooper BA, Miaskowski C. The effect of symptom clusters on functional status and quality of life in women with breast cancer. European Journal of Oncology Nursing. 2010; 14(2):101-10.

12. Eskelinen M, Korhonen R, Selander $\mathrm{T}$, Ollonen P. Beck depression inventory as a predictor of long-term outcome among patients admitted to the breast cancer diagnosis unit: a 25-year cohort study in
Finland. Anticancer research. 2017; 37(2):819-24.

13. Dorros SM, Card NA, Segrin C, Badger TA. Interdependence in women with breast cancer and their partners: an interindividual model of distress. Journal of consulting and clinical psychology. 2010; 78(1):121.

14. Segrin C, Badger TA. Psychological and physical distress are interdependent in breast cancer survivors and their partners. Psychology, health \& medicine. 2014; 19(6): 716-23.

15. Vahdaninia M, Omidvari S, Montazeri A. What do predict anxiety and depression in breast cancer patients? A follow-up study. Social psychiatry and psychiatric epidemiology. 2010; 45(3):355-61.

16. Karakoyun-Celik O, Gorken I, Sahin S, Orcin E, Alanyali H, Kinay M. Depression and anxiety levels in woman under follow-up for breast cancer: relationship to coping with cancer and quality of life. Medical Oncology. 2010; 27(1):108-13

17. Maass SW, Roorda C, Berendsen AJ, Verhaak $\mathrm{PF}$, de Bock GH. The prevalence of long-term symptoms of depression and anxiety after breast cancer treatment: a systematic review. Maturitas. 2015; 82(1):100-8.

18. Fong AJ, Scarapicchia TM, McDonough MH, Wrosch C, Sabiston CM. Changes in social support predict emotional well-being in breast cancer survivors. Psycho-oncology. 2017; 26(5): 664-71.

19. Hughes S, Jaremka LM, Alfano CM, Glaser R, Povoski SP, Lipari AM, et al. Social support predicts inflammation, pain, and depressive symptoms: longitudinal relationships among breast cancer survivors. Psychoneuroendocrinology. 2014; 42:38-44.

20. McDonough MH, Sabiston CM, Wrosch C. Predicting changes in posttraumatic growth and subjective well-being among breast cancer survivors: the role of social support and stress. Psycho-Oncology. 2014; 23(1):114-20.

21. Leung J, Pachana NA, McLaughlin D. Social support and health-related quality of life in women with breast cancer: a longitudinal study. Psycho-Oncology. 2014; 23(9):101420.

22. Coyne E, Wollin J, Creedy DK. Exploration of the family's role and strengths after a young woman is diagnosed with breast cancer: Views of women and their families. European Journal of Oncology Nursing. 2012; 16(2):124-30.

23. Zimet GD, Dahlem NW, Zimet SG, Farley GK. The multidimensional scale of perceived social support. Journal of personality assessment. 1988; 52(1):30-41. 
24. Nazari S, Foroughan M, Mohammadi Shahbolaghi F, Rassouli M, Sadegh Moghadam L, Farhadi A, et al. Analysis of the Psychometric Properties of the Perceived Social Support Scales in Older Adults. Salmand: Iranian Journal of Ageing. 2016; 10(4):210-8.

25. Beck AT, Ward CH, Mendelson M, Mock J, Erbaugh J. An inventory for measuring depression. Archives of general psychiatry. 1961; 4(6): 561-71.

26. Stefan-Dabson K, Mohammadkhani P, Massah-Choulabi O. Psychometrics characteristic of Beck Depression Inventory-II in patients with magor depressive disorder. Archives of Rehabilitation. 2007; 8(1):82-0.

27. Zainal NZ, Nik-Jaafar NR, Baharudin A, Sabki ZA, Ng CG. Prevalence of depression in breast cancer survivors: a systematic review of observational studies. Asian Pacific Journal of Cancer Prevention. 2013; 14(4):2649-56.
28. Jeong K, Heo J, Tae Y. Relationships among distress, family support, and health promotion behavior in breast cancer survivors. Asian Oncology Nursing. 2014; 14(3):146-54.

29. Kamen C, Cosgrove V, McKellar J, Cronkite R, Moos R. Family support and depressive symptoms: a 23-year follow-up. Journal of clinical psychology. 2011; 67(3):215-23.

30. Ferraro PM, Taylor EN, Eisner BH. History of Kidney Stones and the Risk of Coronary Heart Disease. Psychology and Health. 2013; 310(4):408-15.

31. Salakari M, Pylkkänen L, Sillanmäki L, Nurminen R, Rautava P, Koskenvuo M, et al. Social support and breast cancer: A comparatory study of east cancer survivors, women with mental depression, women with hypertension and healthy female controls. The Breast. 2017; 35:85-90. 